\title{
Comparison of Reconfigurations Using Deterministic Approach for Global Assessment of Operational State in Power System
}

\author{
Boris Cintula ${ }^{1)}$, Žaneta Eleschová ${ }^{2)}$, Anton Belán̆ ${ }^{3)}$ and Peter Janiga ${ }^{4)}$ \\ 1) 2) 3) 4) Slovak University of Technology in Bratislava, Faculty of Electrical Engineering and Information Technology, \\ Institute of Power and Applied Electrical Engineering, Bratislava, Slovak Republic, \\ e-mail: ${ }^{1)}$ boris.cintula@stuba.sk, ${ }^{2)}$ zaneta.eleschova@stuba.sk, ${ }^{3)}$ anton.belan@stuba.sk, ${ }^{4)}$ peter.janiga@stuba.sk
}

\begin{abstract}
This article deals with the analysis of impact reconfiguration on the power system operational state. The stated analysis assess results of the simulated calculations of $\mathrm{N}-1$ events with the aim to obtain a more complex view of the security criterion $\mathrm{N}-1$ use in comparison with the current methods and procedures being in practice. Methodologies based on the deterministic approach arising from calculations of steady states with the global assessment of the power system operational states are presented. The article objective is to comprehensively compare the selected operational states especially different reconfiguration variants in a power system.
\end{abstract}

Keywords - security criterion N-1, deterministic approach, reconfiguration, global assessment, operational state, power system

\section{INTRODUCTION}

Currently a great attention is paid to the increase of security and operation of power systems. Several large system failures occurring worldwide in the previous decades affirm significance and need to develop this philosophy. There are examples of it such as the power system failures of blackout type in USA, Italy or a splitting into islanding operations in a synchronically interconnected power system in Europe. The reason for occurrence of such failures is a conjunction of several events; nevertheless, all the cases show the only common violated indicator which is a failure to meet the performance of the security criterion $\mathrm{N}-1$.

Nowadays, within synchronously interconnected system the European Awareness System is used for exchange of online information evaluating the security criterion $\mathrm{N}-1$ analysis among other operating quantities. Based on the monitoring of the operational states, particular categories of the operational states are distinguished by means of the traffic light. In order to comply with the security criterion $\mathrm{N}-1$ as one of the input parameters to determine the overall operational state of the power system: this criterion is assessed "binary", i.e. "condition of criterion N-1 is met" or "condition of criterion N-1 is not met".

\section{Methodology of Global AsSESSMENT}

The methodology of global assessment of the power system operational state is based on an analysis of simulation results of the security criterion $\mathrm{N}-1$ considering various steady states with regard to changes of load, transit, topology and power system development.

In general, the deterministic approach is possible to define as a principle where effect of each kind is possible to determine entirely and definitely.

Subject of the deterministic approach for a classification of the operational state is the assessment of consequences after $\mathrm{N}-1$ events (contingencies) on the basis of limitations and criteria determined in advance.

The proposed methodology using the deterministic approach is based on the following procedure:

\section{Step 1}

Simulation calculations of the N-1 security criterion (internal contingency), i.e. repeated calculation of the reference steady state for outage of each power line within the transmission power system. The aim of the calculations is to obtain the loading values in $\mathrm{N}$ state and $\mathrm{N}-1$ states of all power lines (after all contingencies) in the responsibility area.

\section{Step 2}

Based on the contingency simulation results in the responsibility area LODF values (Line Outage Distribution Factor) are subsequently calculated. The LODF value determines the percentage of power flow on the present power line that will be shown up on other transmission power lines after the outage of this line. Simply, LODFs are a sensitivity measure of how a change in a line status affects the flows on other lines in the power system.

For the purpose of methodology proposal the LODF is calculated according to the following formula:

$$
L O D F_{V x}^{V y}=\left(\frac{P_{n-1}^{V y}-P_{n}^{V y}}{P_{n}^{V x}} .100\right)
$$

where

$\mathrm{P}^{\mathrm{Vy}}{ }_{\mathrm{n}-1}$ is a loading of the assessed power line "Vy" after outage of the power line "Vx",

$\mathrm{P}^{\mathrm{Vy}}{ }_{\mathrm{n}}$ - a loading of the assessed power line "Vy" in time without power lines being turned off (state $\mathrm{N}$ ), $\mathrm{P}^{\mathrm{Vx}}{ }_{\mathrm{n}}$ - a loading of the power line " $\mathrm{Vx}$ " in time without power lines being turned off (state $\mathrm{N}$ ). 
Within the contingency list (N-1 events) all power lines in the responsibility area are included while the ODF calculation is performed only for loading changes of the system power lines, i.e. loading changes of the radial power lines (radial feeder to generation and consumption) are not considered due to an high impact of the result distortion. Among the partial distortion causes of the methodology results are included:

- Small loading changes of the radial power lines after the outage of the system power lines - consequence of the voltage fluctuation in the end node of the power line.

- Significant loading changes after the outage of the radial power lines (accepted in cases for parallel connection of the radial power lines).

\section{Step 3}

Further, in the methodology of global assessment only positive loading changes are considered. It is necessary to distinguish significant loading changes from the less significant applying the data filter.

The data filter of increased loading changes is defined by common meeting of the below stated conditions where (2) defines a minimum loading change of the power line after contingency (N-1 event) against state $\mathrm{N}$ and (3) a minimum loading value of the given power line after contingency ( $\mathrm{N}-1$ calculation) with respect to a nominal load.

$$
\begin{gathered}
\frac{P_{V}^{N-1}}{P_{V}^{N}} \geq 0,05 \\
I_{V}^{N-1} \geq 0,3 \cdot I_{n V}
\end{gathered}
$$

Step 4

An overall assessment of the power system operational states is based on perspectives defining four weight factors (WF):

\section{- Perspective on power lines loading}

i. WF1 is determined by a p.u. value of the most loaded power line in the steady state ( $\mathrm{N}$ state) related to the nominal loading.

$$
\max \left(i_{V j}^{V i}\right)_{N} \Rightarrow V F 1
$$

$$
\begin{aligned}
& V i \in\langle 1 ; 51\rangle \wedge i \neq 1,2,3,4,5,6,7,8,9,15,16 \\
& V j \in\langle 1 ; 51\rangle
\end{aligned}
$$

Where

$\mathrm{i}$ is a p.u. value of the power line loading,

$\mathrm{Vi}$ - number of the system power lines in the responsibility area,

$\mathrm{Vj}$ - total number of the power lines in the responsibility area,

$\mathrm{N}-$ state $\mathrm{N}$.

ii. WF2 is determined by a p.u. value of the most loaded power line after all contingencies calculation in the responsibility area related to the nominal loading.

$$
\begin{aligned}
& \max \left(i_{V j}^{V i}\right)_{N-1} \Rightarrow V F 2 \\
& V i \in\langle 1 ; 51\rangle \wedge i \neq 1,2,3,4,5,6,7,8,9,15,16 \\
& V j \in\langle 1 ; 51\rangle
\end{aligned}
$$

Where

$i$ is a p.u. value of the power line loading,

$\mathrm{Vi}$ - number of the system power lines in the responsibility area,

$\mathrm{Vj}$ - total number of the power lines in the responsibility area,

$\mathrm{N}-1$ - state after all contingencies.

- System perspective on the number of the most affected and effecting power lines

iii. WF3 is determined by a p.u. value of the number of the affected power lines after all contingencies calculation related to the number of the system power lines.

$$
\frac{n_{V_{-} P O V P}}{n_{V_{-} C P S V}} \Rightarrow V F 3
$$

Where

$\mathrm{n}_{\mathrm{V} \_P O V P}$ is a number of the affected power lines, where the affected power line is considered a power line with at least one significant positive loading change after any contingency,

$\mathrm{n}_{\mathrm{V} \_ \text {CPSV }}$ - number of the system power lines in the responsibility area.

iv. WF4 is determined by a p.u. value of the number of the effecting power lines after all contingencies related to the total number of the power lines.

$$
\frac{n_{V_{-} P V P L}}{n_{V_{-} C P V}} \Rightarrow V F 4
$$

Where

$\mathrm{n}_{\mathrm{V} \text { PVPL }}$ is a number of the effecting power lines, where the effecting power line is considered a power line which outage will cause at least one significant positive loading change of any assessed power line,

$\mathrm{n}_{\mathrm{V}_{-} \mathrm{CPV}}-$ total number of the power lines in the responsibility area.

For the above described p.u. values weight factors values determining their sizes and severity levels (TABLE I, TABLE II, TABLE III) are appointed. The definition of the severity levels considers for the power line loading an uncertainty of mathematical models (model accuracy, scheduled loading, etc.) and the system perspective is based on the analysis of a large number results of the simulation calculations of the steady states.

A proposal of weight factor values can be adjusted in accordance to the purpose of assessment, e.g. the operational planning and real time operation for on-line monitoring of the power system operation, defence plan or development of the power system. 
TABLE I.

SIZES AND SEVERITY LEVELS OF WEIGHT FACTOR WF1 EXPRESSING POWER LINES LOADING IN STATE N

\begin{tabular}{|c|c|}
\hline Intervals (p.u.) of Power Line Loading in State $\mathbf{N}$ & WF1 \\
\hline$<1 ; \infty)$ & 1 \\
\hline$<0.8 ; 1)$ & 0.8 \\
\hline$<0.6 ; 0.8)$ & 0.6 \\
\hline$<0 ; 0.6)$ & 0.5 \\
\hline
\end{tabular}

TABLE II.

SIZES AND SEVERITY LEVELS OF WEIGHT FACTOR WF2 EXPRESSING POWER LINES LOADING AFTER CONTINGENCY

\begin{tabular}{|c|c|}
\hline Intervals (p.u.) of Power Line Loading after Contingency & WF2 \\
\hline$<1 ; \infty)$ & 1 \\
\hline$<0.9 ; 1)$ & 0.8 \\
\hline$<0.8 ; 0.9)$ & 0.6 \\
\hline$<0 ; 0.8)$ & 0.5 \\
\hline
\end{tabular}

TABLE III.

SIZES AND SEVERITY LEVELS OF WEIGHT FACTORS WF3, WF4

EXPRESSING SYSTEM PERSPECTIVE ON NUMBER OF AFFECTED AND EFFECTING POWER LINES

\begin{tabular}{|c|c|}
\hline $\begin{array}{c}\text { Intervals (p.u.) of Number of Affected and Effecting } \\
\text { Power Lines }\end{array}$ & WF3, WF4 \\
\hline$<0.75 ; 1>$ & 1 \\
\hline$<0.65 ; 0.75)$ & 0.8 \\
\hline$<0.5 ; 0.65)$ & 0.6 \\
\hline$<0 ; 0.5)$ & 0.5 \\
\hline
\end{tabular}

\section{Step 5}

The limit of the weight factor values is reassessed on the basis of the sensitivity analysis for considering of severity extent of the particular weight factors. Based on the sensitivity analysis of several steady states results the weight factor intervals are reassessed. Furthermore, the inter-levels of weight factors are expressing an approximation of p.u. values from the margin of the nearest worse level of the weight factors (TABLE IV, TABLE V, TABLE VI). The result of the sensitivity analysis consideration is more precise partial as well as the overall assessment of the power system operation state. In this manner it is possible to prevent determination of a less serious state to be serious and clearly differentiate more serious state from other states.

TABLE IV.

SIZES AND SEVERITY LEVELS OF WEIGHT FACTOR WF1 EXPRESSING POWER LINES LOADING IN STATE N CONSIDERING SENSITIVITY ANALYSIS

\begin{tabular}{|c|c|}
\hline \multicolumn{2}{|c|}{ Sensitivity Analysis } \\
\hline Intervals (p.u.) of Power Line Loading in State $\mathbf{~}$ & WF1 \\
\hline$<1 ; \infty)$ & 1 \\
\hline$<0.9 ; 1)$ & 0.9 \\
\hline$<0.8 ; 0.9)$ & 0.8 \\
\hline$<0.7 ; 0.8)$ & 0.7 \\
\hline$<0.6 ; 0.7)$ & 0.6 \\
\hline$<0.5 ; 0.6)$ & 0.5 \\
\hline$<0 ; 0.5)$ & 0.4 \\
\hline
\end{tabular}

TABLE V.

SIZES AND SEVERITY LEVELS OF WEIGHT FACTOR WF2 EXPRESSING POWER LINES LOADING AFTER CONTINGENCY CONSIDERING SENSITIVITY ANALYSIS

\begin{tabular}{|c|c|}
\hline \multicolumn{2}{|l|}{ Sensitivity Analysis } \\
\hline Intervals (p.u.) of Power Line Loading after Contingency & WF2 \\
\hline$<1 ; \infty)$ & $1^{\mathrm{a}}$ \\
\hline$<0.9 ; 1)$ & 0.9 \\
\hline$<0.8 ; 0.9)$ & 0.7 \\
\hline$<0.7 ; 0.8)$ & 0.5 \\
\hline$<0 ; 0.7)$ & 0.4 \\
\hline
\end{tabular}

${ }^{\mathrm{a} C}$ Criterion $\mathrm{N}-1$ performance is not met for 1 power line

${ }^{\mathrm{b}}$ Criterion $N$-1 performance is not met for 2 power lines at least

TABLE VI.

SIZES AND SEVERITY LEVELS OF WEIGHT FACTORS WF3, WF4 EXPRESSING SYSTEM PERSPECTIVE ON NUMBER OF AFFECTED AND EFFECTING POWER LINES CONSIDERING SENSITIVITY ANALYSIS

\begin{tabular}{|c|c|}
\hline \multicolumn{2}{|c|}{ Sensitivity Analysis } \\
\hline $\begin{array}{c}\text { Intervals (p.u.) of Number of Affected and Effecting Power } \\
\text { Lines }\end{array}$ & WF3, WF4 \\
\hline$<0.75 ; 1>$ & 1 \\
\hline$<0.7 ; 0.75)$ & 0.9 \\
\hline$<0.65 ; 0.7)$ & 0.8 \\
\hline$<0.6 ; 0.65)$ & 0.7 \\
\hline$<0.5 ; 0.6)$ & 0.6 \\
\hline$<0.4 ; 0.5)$ & 0.5 \\
\hline$<0 ; 0.4)$ & 0.4 \\
\hline
\end{tabular}

Step 6

Eventually, the overall assessment of the operational state is determined based on the product of all weight factors. The proposed methodology includes two exemptions for the global assessment of the operational state. By the exception it is meant the direct determination of the overall assessment of the operational state, i.e. it determines the overall assessment as "emergency" in the case of validity of any following conditions:

- If the loading value of the most loaded power line in state $\mathrm{N}$ is higher than $100 \%$,

- If at least two WFs equal 1, then the overall assessment of the operation state determined by the product of all WFs is one state worse.

TABLE VII.

Classification of Overall Global AsSESSMENT OF POWER SYSTEM OPERATIONAL STATE

\begin{tabular}{|c|c|c|}
\hline $\begin{array}{c}\text { Overall } \\
\text { Assessment of } \\
\text { Power System } \\
\text { Operational } \\
\text { State }\end{array}$ & $\begin{array}{c}\text { Intervals of Products Size } \\
\text { (WF1 - WF4) }\end{array}$ & $\begin{array}{c}\text { Color } \\
\text { Determination }\end{array}$ \\
\hline Normal & $\langle 0.0256 ; 0.05>$ & Green \\
\hline Alarm & $(0.05 ; 0.2058>$ & Yellow \\
\hline Alert & $(0.2058 ; 0.5832>$ & Orange \\
\hline Emergency & $(0.5832 ; 1>$ & Red \\
\hline
\end{tabular}




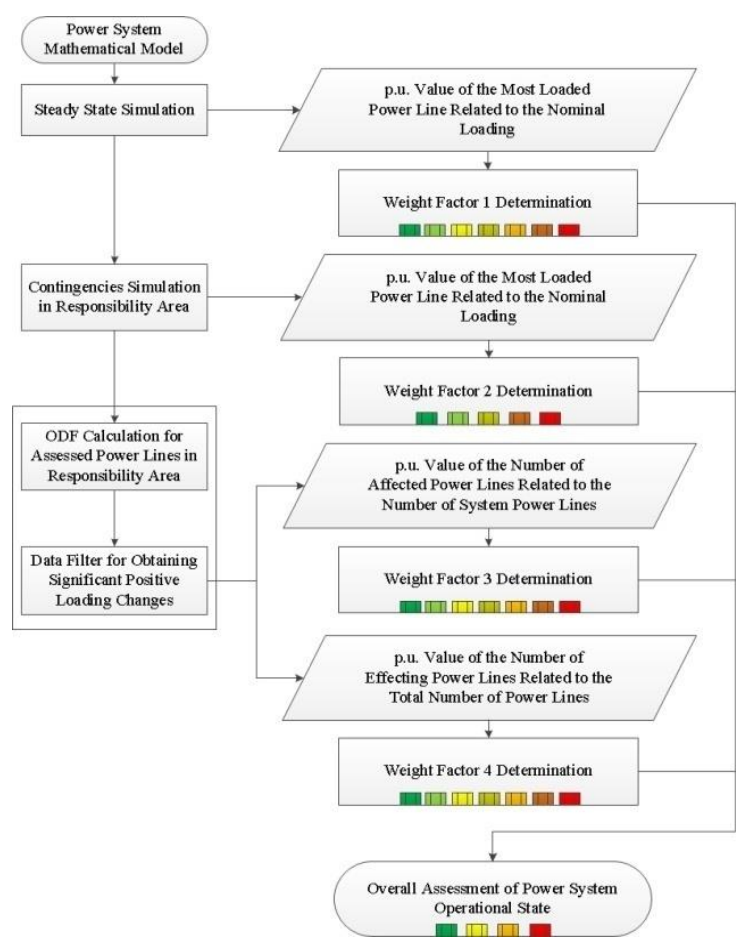

Fig. 1. Flowchart of methodology of global assessment.

\section{RECONFIGURATION ASSESSMENT}

Among the measures to solve situation of the $\mathrm{N}-1$ criterion meeting possible implemented by transmission system operators (TSOs) belong as follows:

- cancellation of the scheduled maintenance or break of all works in real-time operation utilizing standby time,

- coordinated topology changes (network configuration),

- use of phase shifter transformers,

- contracted generation re-dispatch within the TSO own control areas,

- reduction of interconnection capacities

- manual load shedding (consumption limiting plan in SR).

The reconfigurations are effective remedial actions to restore the $\mathrm{N}-1$ criterion meeting and therefore the objective of the article is to focus on the reconfiguration and comprehensively compare selected different reconfiguration variants in the power system.

Verification of the proposed methodology using the deterministic approach was gradually performed for a large number of different operational states.

The aim of this chapter is to verify the methodology for system topology changes and result comparison with the steady state before the reconfiguration. Simulations are performed by means of the mathematical model of the power system in accordance with the following topologies:

- Reference model of the power system (Fig. 2),

- Reconfiguration in the substation Rz18_1 (Fig. 3),

- Reconfiguration in the substation Rz14 (Fig. 3),

- Reconfiguration in the substation Rz6_1 (Fig. 3),

- Reconfiguration in the substation Rz6_1+Rz14 (Fig. 3),

- Reconfiguration in the substation Rz18_1+Rz6_1+ Rz14 (Fig. 3)

- Reconfiguration in the substation Rz6_2 (Fig. 4),

- Reconfiguration in the substation Rz18_2+Rz34 (Fig. 5),

- Reconfiguration in the substation Rz18_1+Rz6_1 (Fig. 3),

- Reconfiguration in the substation Rz18_1+Rz6_2 (Fig. 4).

Based on the result analysis of the steady state before the reconfiguration values for loading of the system power lines in the state $\mathrm{N}$ and after all contingencies $(\mathrm{N}-1$ simulations), as well as values of number of the affected and effecting power lines under the present methodology are determined (TABLE VIII).

Partial results: the most loaded power line in the state $\mathrm{N}$ $(70,7 \%)$, the most loaded power line after all contingencies $(101,6 \%)$, number of the significantly affected power lines $(52,5 \%)$ and number of the significantly effecting power lines $(58,8 \%)$. The steady state before the reconfiguration is close beyond the $\mathrm{N}-1$ security criterion meeting. Above, there are stated only summary results, but the methodology also provides detailed identification of the affected and effecting power lines.

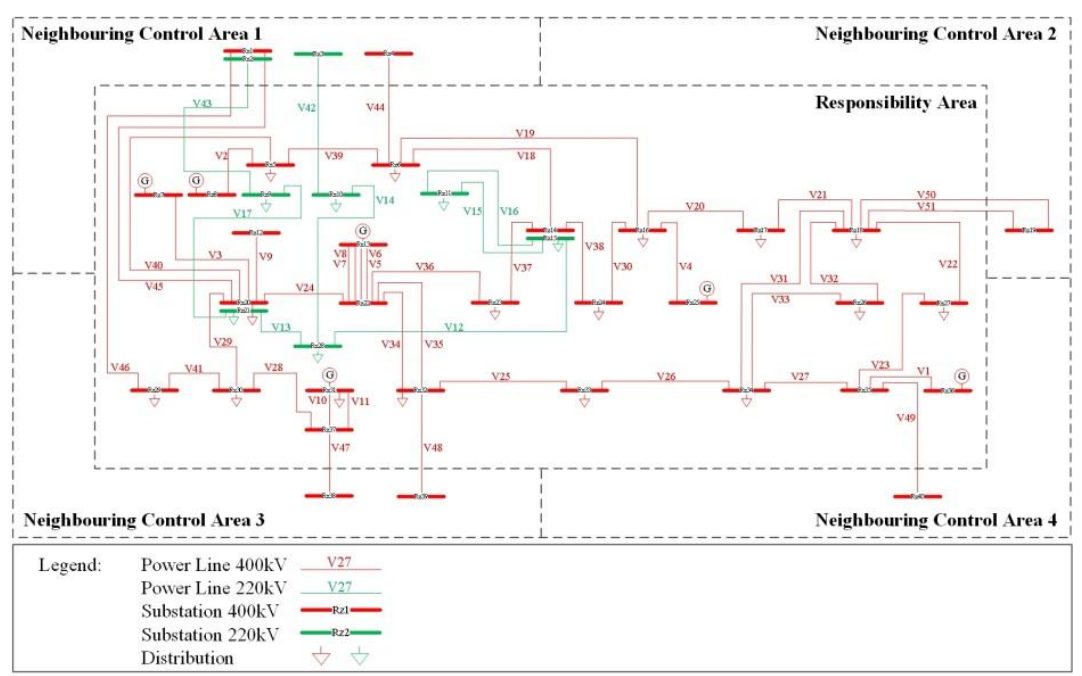

Fig. 2. Reference model topology of the power system. 


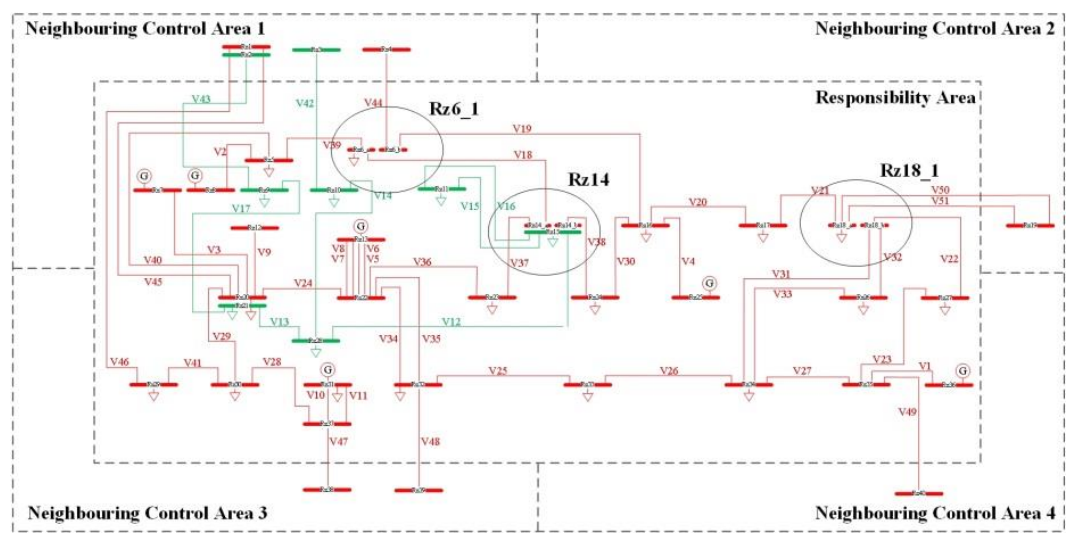

Fig. 3. Reconfiguration in particular substations (and its combinations).

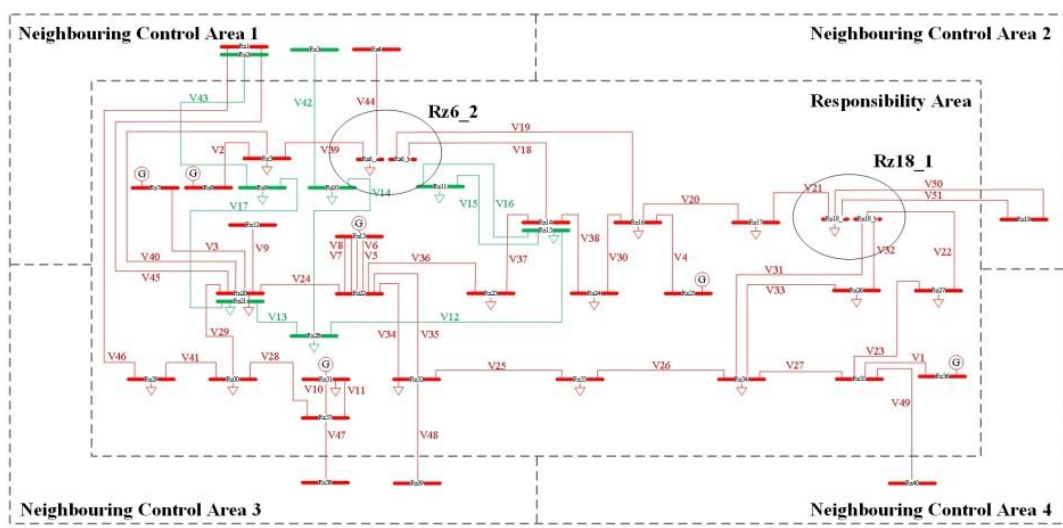

Fig. 4. Reconfiguration in particular substations (and its combinations).

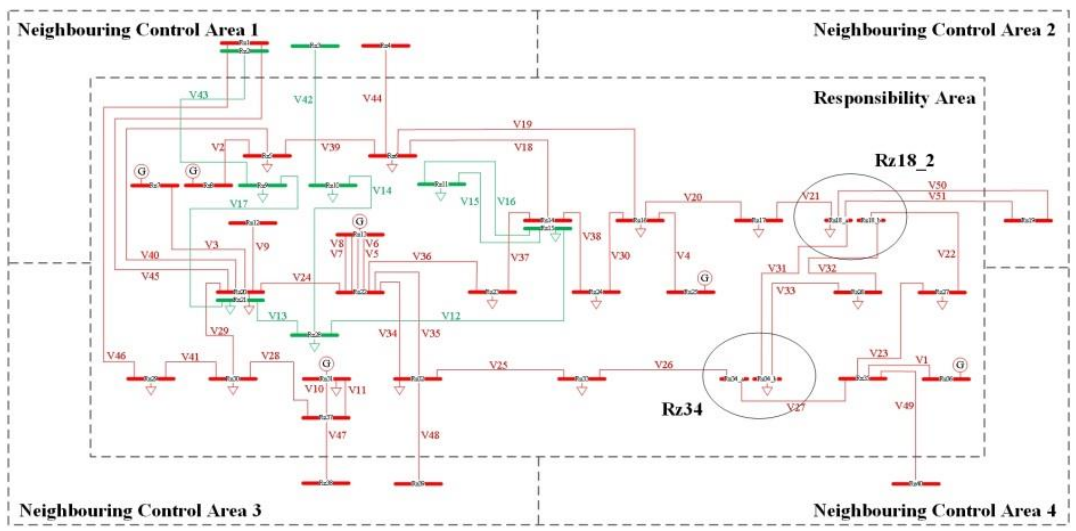

Fig. 5. Reconfiguration in particular substations (and its combinations).

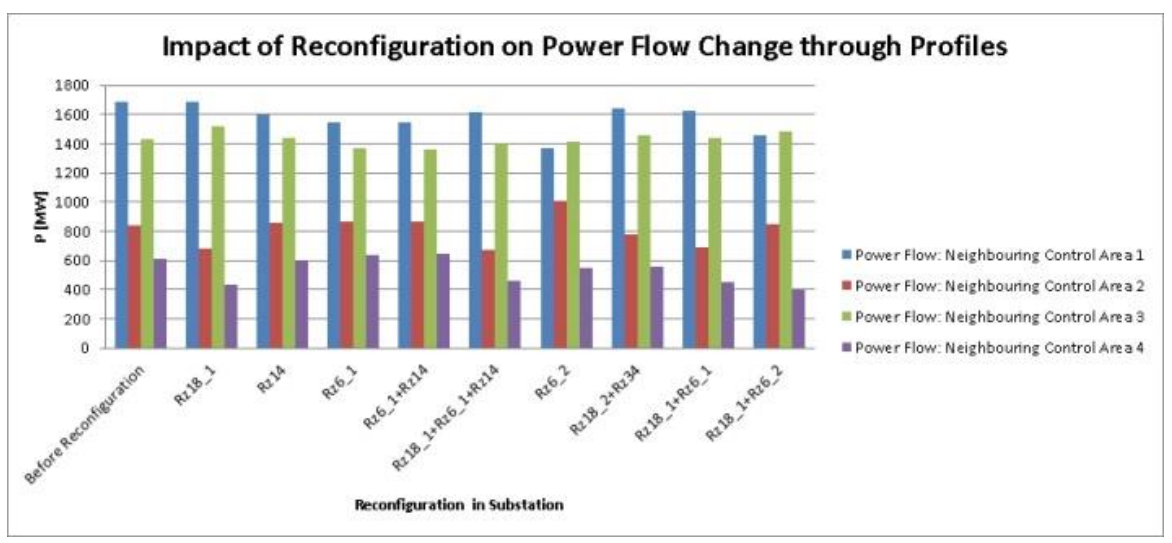

Fig. 6. Impact of reconfiguration on power flow change through profiles. 


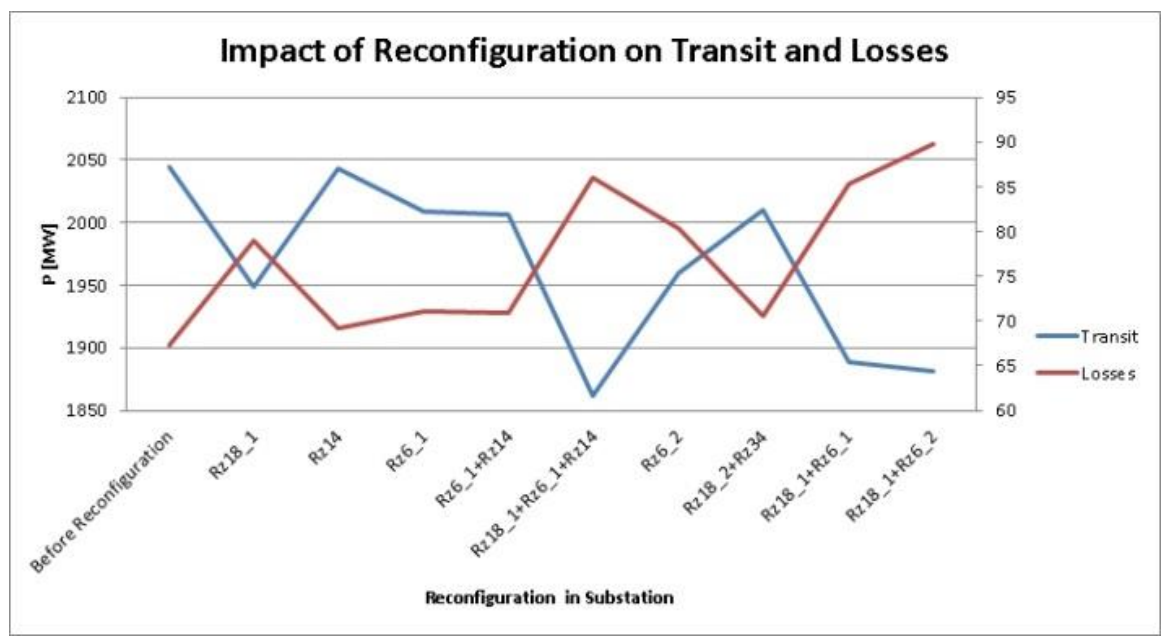

Fig. 7. Impact of reconfiguration on transit and losses.

TABLE VIII

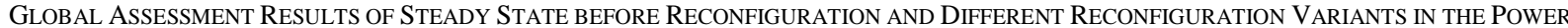
SYSTEM

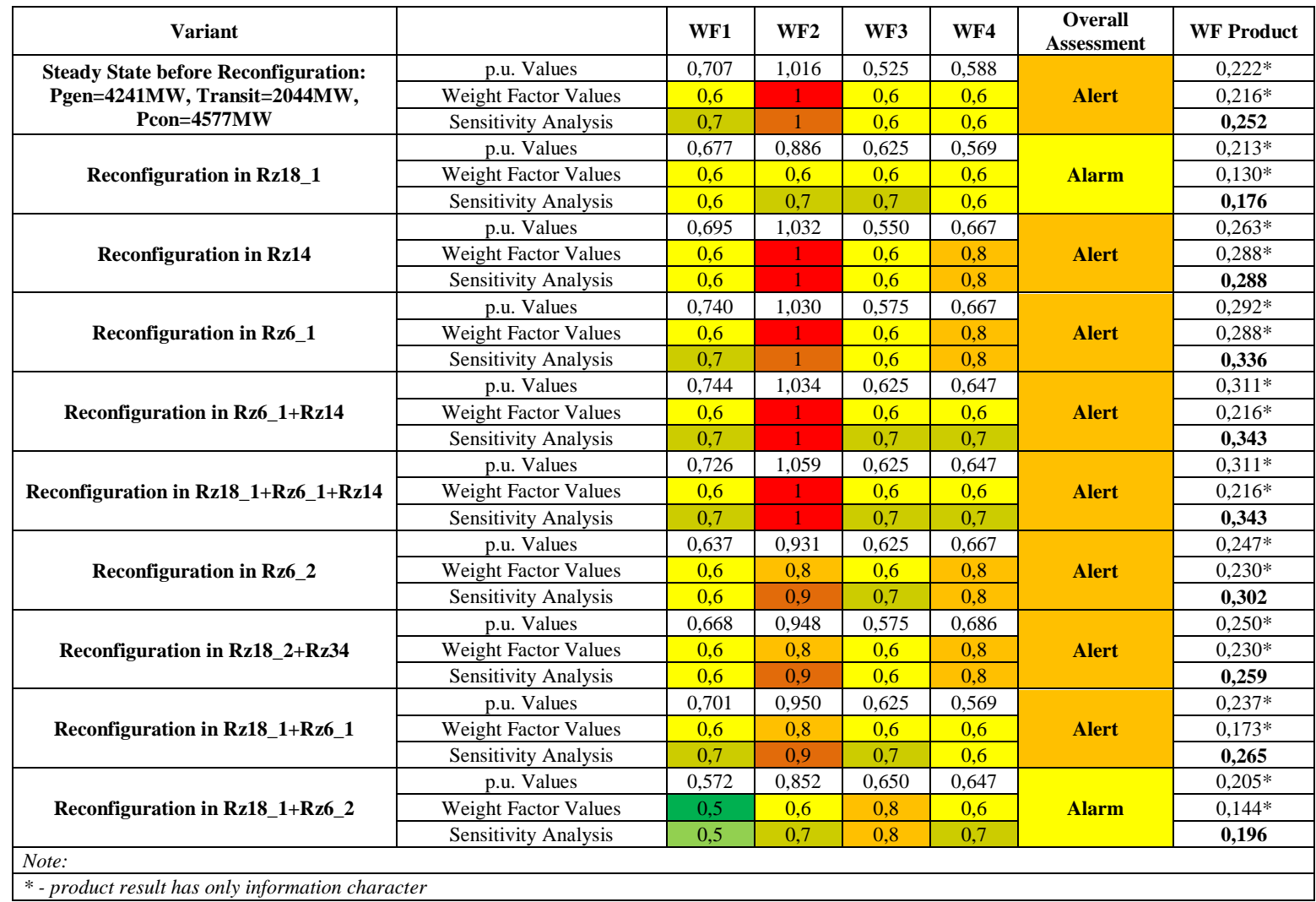


TABLE IX.

SUMMARY OF POWER GENERATION, CONSUMPTION AND TRANSMISSION - STEADY STATE BEFORE RECONFIGURATION AND DIFFERENT RECONFIGURATION VARIANTS

\begin{tabular}{|c|c|c|c|c|c|c|c|c|c|c|}
\hline $\begin{array}{l}\text { Reconfiguration in } \\
\text { Substation/Values }\end{array}$ & $\begin{array}{c}\begin{array}{c}\text { Steady State } \\
\text { before } \\
\text { Reconfiguration }\end{array} \\
\end{array}$ & Rz18_1 & Rz14 & Rz6_1 & $\begin{array}{l}\text { Rz6_1 } \\
+ \text { Rz14 }\end{array}$ & $\begin{array}{l}\text { Rz18_1 } \\
\text { +Rz6_1 } \\
\text { +Rz14 }\end{array}$ & Rz6_2 & $\begin{array}{c}\text { Rz18_2 } \\
+\mathrm{Rz34}\end{array}$ & $\begin{array}{l}\text { Rz18_1 } \\
+ \text { Rz6_1 }\end{array}$ & $\begin{array}{l}\text { Rz18_1 } \\
+ \text { Rz6_2 }\end{array}$ \\
\hline $\begin{array}{c}\text { Total Generation } \\
{[\mathrm{MW}]}\end{array}$ & 4240,6 & 4240,6 & 4240,6 & 4240,6 & 4240,6 & 4240,6 & 4240,6 & 4240,6 & 4240,6 & 4240,6 \\
\hline Total Load [MW] & 4576,8 & 4576,8 & 4576,8 & 4576,8 & 4576,8 & 4576,8 & 4576,8 & 4576,8 & 4576,8 & 4576,8 \\
\hline Total Losses [MW] & 67,36 & 79 & 69,26 & 71,1 & 70,97 & 86,05 & 80,27 & 70,54 & 85,34 & 89,8 \\
\hline $\begin{array}{c}\text { Total Load } \\
\text { Considering Total } \\
\text { Losses [MW] }\end{array}$ & 4644,16 & 4655,8 & 4646,06 & 4647,9 & 4647,77 & 4662,85 & 4657,07 & 4647,34 & 4662,14 & 4666,6 \\
\hline Balance [MW] & $-336,2$ & $-336,2$ & $-336,2$ & $-336,2$ & $-336,2$ & $-336,2$ & $-336,2$ & $-336,2$ & $-336,2$ & $-336,2$ \\
\hline Transit $[\mathrm{MW}]$ & 2044,16 & 1948,69 & 2042,98 & 2008,68 & 2006,64 & 1861,64 & 1959,78 & 2009,81 & 1888,38 & 1881,34 \\
\hline $\begin{array}{l}\text { Power Flow: Assessed } \\
\text { Power System - } \\
\text { Neighbouring Control } \\
\text { Area } 1[\mathrm{MW}]\end{array}$ & $-1686,55$ & $-1686,55$ & $-1594,92$ & $-1547,64$ & $-1545,75$ & $-1614,41$ & $-1365,03$ & $-1639,05$ & $-1620,72$ & $-1455,9$ \\
\hline $\begin{array}{l}\text { Power Flow: Assessed } \\
\text { Power System - } \\
\text { Neighbouring Control } \\
\text { Area } 2[\mathrm{MW}]\end{array}$ & $-841,46$ & $-677,34$ & $-853,52$ & $-868,34$ & $-868,06$ & $-669,48$ & $-1011,22$ & $-777,5$ & $-689,2$ & $-851,44$ \\
\hline $\begin{array}{l}\text { Power Flow: Assessed } \\
\text { Power System - } \\
\text { Neighbouring Control } \\
\text { Area } 3[\mathrm{MW}]\end{array}$ & 1432,13 & 1514,45 & 1441,83 & 1368,17 & 1362,81 & 1403,62 & 1408,5 & 1453,71 & 1441,55 & 1484,66 \\
\hline $\begin{array}{l}\text { Power Flow: Assessed } \\
\text { Power System - } \\
\text { Neighbouring Control } \\
\text { Area } 4 \text { [MW] }\end{array}$ & 612,03 & 434,24 & 601,15 & 640,51 & 643,83 & 458,02 & 551,28 & 556,1 & 446,83 & 396,68 \\
\hline \multicolumn{11}{|l|}{ Notes: } \\
\hline \multicolumn{11}{|c|}{ Pgen - Generation in Responsibility Area } \\
\hline \multicolumn{11}{|c|}{ Transit - Transit through Responsibility Area } \\
\hline Pcon-Consumption in $R$ & ponsibility Area & & & & & & & & & \\
\hline
\end{tabular}

TABLE X.

Summary of Voltage Phase Changes in Particular Substations AFter Reconfiguration

\begin{tabular}{|c|c|c|c|c|c|c|c|c|c|c|c|}
\hline & Transit [MW] & $\begin{array}{c}\text { Transit } \\
\text { Decrease } \\
{[\mathrm{MW}]}\end{array}$ & $\begin{array}{c}\text { Voltage } \\
\text { Phase in } \\
\text { 1st } \\
\text { Substation } \\
\text { on Bus- } \\
\text { Bar x_a } \\
\left.{ }^{\circ}{ }^{\circ}\right]\end{array}$ & $\begin{array}{c}\text { Voltage } \\
\text { Phase in } \\
\text { 1st } \\
\text { Substation } \\
\text { on Bus- } \\
\text { Bar x_b } \\
{\left[{ }^{\circ}\right]}\end{array}$ & $\begin{array}{c}\text { Voltage } \\
\text { Phase in } \\
\text { 2nd } \\
\text { Substation } \\
\text { on Bus- } \\
\text { Bar } x_{-} \text {a } \\
{\left[^{\circ}\right]}\end{array}$ & $\begin{array}{c}\text { Voltage } \\
\text { Phase in } \\
\text { 2nd } \\
\text { Substation } \\
\text { on Bus- } \\
\text { Bar x_b } \\
{\left[^{\circ}\right]}\end{array}$ & $\begin{array}{c}\text { Voltage } \\
\text { Phase in } \\
\text { 3rd } \\
\text { Substation } \\
\text { on Bus- } \\
\text { Bar x_a } \\
{\left[{ }^{\circ}\right]}\end{array}$ & $\begin{array}{c}\text { Voltage } \\
\text { Phase in } \\
\text { 3rd } \\
\text { Substation } \\
\text { on Bus- } \\
\text { Bar x_b } \\
{\left[{ }^{\circ}\right]}\end{array}$ & $\begin{array}{c}\Delta \text { Voltage } \\
\text { Phase in 1st } \\
\text { Substation } \\
{\left[^{\circ}\right]}\end{array}$ & $\begin{array}{c}\Delta \text { Voltage } \\
\text { Phase in 2nd } \\
\text { Substation } \\
{\left[^{\circ}\right]}\end{array}$ & $\begin{array}{c}\Delta \text { Voltage } \\
\text { Phase in 3rd } \\
\text { Substation } \\
{\left[^{\circ}\right]}\end{array}$ \\
\hline $\begin{array}{l}\text { Steady State before } \\
\text { Reconfiguration: } \\
\text { Pgen=4241MW, } \\
\text { Transit=2044MW, } \\
\text { Pcon=4577MW }\end{array}$ & 2044,16 & - & - & - & - & - & - & - & - & - & - \\
\hline $\begin{array}{l}\text { Reconfiguration } \\
\text { in Rz18_1 }\end{array}$ & 1948,69 & $-95,47$ & $-11,898$ & $-22,741$ & - & - & - & - & 10,843 & - & - \\
\hline $\begin{array}{l}\text { Reconfiguration } \\
\text { in Rz14 }\end{array}$ & 2042,98 & $-1,18$ & $-12,281$ & $-15,864$ & - & - & - & - & 3,583 & - & - \\
\hline $\begin{array}{l}\text { Reconfiguration } \\
\text { in Rz6_1 }\end{array}$ & 2008,68 & $-35,48$ & $-9,282$ & $-14,91$ & - & - & - & - & 5,628 & - & - \\
\hline $\begin{array}{l}\text { Reconfiguration } \\
\text { in Rz6_1+Rz14 }\end{array}$ & 2006,64 & $-37,52$ & $-9,147$ & $-15,123$ & $-15,307$ & $-14,695$ & - & - & 5,976 & 0,612 & - \\
\hline $\begin{array}{l}\text { Reconfiguration } \\
\text { in Rz18_1+Rz6_1+Rz14 }\end{array}$ & 1861,64 & $-182,52$ & $-10,427$ & $-23,953$ & $-6,851$ & $-17,189$ & $-17,444$ & $-12,547$ & 13,526 & 10,338 & 4,897 \\
\hline $\begin{array}{l}\text { Reconfiguration } \\
\text { in Rz6_2 }\end{array}$ & 1959,78 & $-84,38$ & $-19,978$ & $-7,706$ & - & - & - & - & 12,272 & - & - \\
\hline $\begin{array}{l}\text { Reconfiguration } \\
\text { in Rz18_2+Rz34 }\end{array}$ & 2009,81 & $-34,35$ & $-14,445$ & $-17,699$ & $-19,23$ & $-15,932$ & - & - & 3,254 & 3,298 & - \\
\hline $\begin{array}{l}\text { Reconfiguration } \\
\text { in Rz18_1+Rz6_1 }\end{array}$ & 1888,38 & $-155,78$ & $-11,249$ & $-23,653$ & $-8,004$ & $-15,436$ & - & - & 12,404 & 7,432 & - \\
\hline $\begin{array}{l}\text { Reconfiguration } \\
\text { in Rz18_1+Rz6_2 }\end{array}$ & 1881,34 & $-162,82$ & $-15,112$ & $-24,876$ & $-19,057$ & $-7,705$ & - & - & 9,764 & 11,352 & - \\
\hline
\end{tabular}

Results of the power line loading in the state N, after all contingencies, number of the affected and effecting power lines are determined by the values of weight factors: WF1WF4. Based on their product the overall assessment of the power system operation for a particular reconfiguration stated in TABLE VIII is determined.

The global assessment of the simulated operational states is classified as "alarm" for the reconfiguration in the substations Rz18_1 and simultaneous reconfigurations in Rz18_1+Rz6_2.Other simulated operational states of the reconfigurations are classified as "alert". Based on the summary of the survey results (TABLE IX) it is not obvious decrease of the power transit through the responsibility area for all reconfiguration variants. A detailed overview of the transit changes through the power system and power flows in particular profiles after a reconfiguration is shown in Figs. 6 and 7.

The primary objective of the reconfiguration is to ensure regular N-1 security criterion meeting. According to the results in TABLE VIII the reconfiguration objective is not met for variants in the substation Rz6_1 (one overloaded power line), Rz14, Rz6_1+Rz14 and Rz18_1+Rz6_1+Rz14Rz6_1 (two overloaded power lines). 
One of the serious disadvantages is the significant increase of losses in the transmission system in the control area. Stated fact was determined by all simulated operational states (Fig. 7.). Other potential disadvantages include the reliability reduction of the transmission system and distribution system in the control area, maintenance restriction and reconstruction work restriction. There is also a potential problem with synchronization conditions in case of return to the base state, but this case was not confirmed by simulated operational states (TABLE X).

Under the current rules of the power system control the operation is considered secured after the restore of the N-1 security criterion meeting. However, this idea has not to be correct, as confirmed by the results of the global assessment according to the proposed methodology. Based on the analysis of the weight factor values for all reconfiguration variants it is possible to establish that in all stated cases the weight factor values VF3 and VF4 are considerably increased, i.e. there is a significant increase of the number of the affected and effecting power lines. That means, the power system is substantially "vulnerable", e.g. in case of other events the situation could lead to the "emergency" of the power system. This fact is confirmed also by the weight factor product, which is for the above mentioned reconfigurations higher than in the steady state before the reconfiguration. Although, the security criterion $\mathrm{N}-1$ is met after the reconfiguration, in fact the operational state of the power system is worse than before the reconfiguration.

Eventually, results obtained by applying the methodology of the global assessment using the deterministic approach do not lead only to classification of the overall operational state, but also provide a comprehensive view on the power system operation expressed by the weight factors.

\section{CONCLUSION}

The submitted paper deals with the methodology of the global assessment of the power system operational states using the deterministic approach and the N-1 security calculations. The present methodology is based on more complex results using of the $\mathrm{N}-1$ security calculations. The proposed methodology does not give only the answer whether the $\mathrm{N}-1$ criterion is met but also how the criterion is met or not met. Based on the results it is possible to differentiate and compare the power system states where $\mathrm{N}-1$ is not met and to formulate which "bad" state is a worse one or, vice versa, to compare the states when $\mathrm{N}-1$ is met and formulate which "good" state is a better one.

Its strong side is universality approved by verification of a large number of operational states and its universal characteristic is a definition of the weight factors by means of which the operational states are classified. Furthermore, sizes and severity levels of the weight factor need to be adjusted for a given regulation area where the methodology will be used. The weight factors need to be identified on the basis of sensitivity analysis of results of a large number of steady states due to a uniqueness of each power system characterized by e.g. extensity, geographical location, structure of power resources and many other attributes.

In accordance with the universality of the proposed methodology it is a wide utilization in practice, especially in the dispatching regulation, operational regulation of the power system, preparation of defence plans as well as with a proposal of power system development plans.

A significant advantage of the proposed methodology is definitely an optimization possibility on the basis of weight factor size in accordance with various levels of a dispatching regulation. It is possible to consider a more conservative perspective for a scheduled operation, defence plan and development of the power system, with a strict modification of single weight factor intervals especially for the reason of reserve due to the mathematic models uncertainty. For the operational regulation it is possible to consider a sensitive margin modification of single weight factor intervals as far as a dispatcher should be informed about a warning state only in case of a higher risk during the power system operation.

Results of the global assessment of the power system topology changes refer to identification of the suitability and successfulness of the reconfigurations regard to the restore of the $\mathrm{N}-1$ criterion meeting. The added value of the methodology is to provide comprehensive information about the power system operational state after the reconfiguration (restoration of the $\mathrm{N}-1$ meeting).

\section{ACKNOWLEDGMENT}

These publications are the result of implementation of the project: "Increase of Power Safety of the Slovak Republic" (ITMS: 26220220077) supported by the Research \& Development Operational Programme funded by the ERDF.
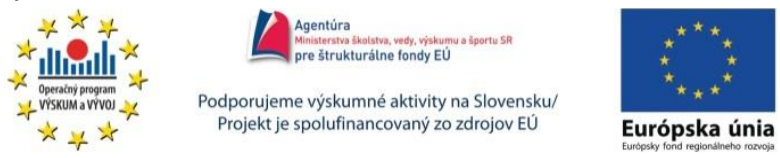

\section{REFERENCES}

[1] P. Kundur, at al, "Definition and classification of power system stability," IEEE Transactions on Power System, vol. 19, no. 3, August 2004, pp. 1387 - 1401. [Online]. Available: IEEE Xplore Digital Library, doi: 10.1109/TPWRS.2004.825981 [Accessed: 25 July. 2016].

[2] J. Machowski, J. W. Bialek, J. R. Bumby, Power System Dynamics: Stability and Control, 2nd ed., John Wiley \& Sons, Ltd.: Chichester, 2008.

[3] Continental Europe Operation Handbook: Operational Security. Brussels - Belgium: ENTSO-E, 2009.

[4] Continental Europe Operation Handbook: Appendix 3: Operational Security. Brussels - Belgium: ENTSO-E, 2009.

[5] Network Code on Operational Security. Brussels - Belgium: ENTSO-E, 2013.

[6] Pravidlá prevádzkovania prenosovej sústavy : Technické podmienky prístupu a pripojenia, pravidlá prevádzkovania prenosovej sústavy. Bratislava: SEPS, a.s., 2014.

[7] Supporting Document for the Network Code on Operational Security, 2nd Edition Final. Brussels - Belgium: ENTSO-E, 2013.

[8] Continental Europe Operation Handbook: Appendix - Policy 5: Emergency Operations: Operational Security. Brussels - Belgium: ENTSO-E, 2010

[9] B. Cintula, Ž. Eleschová, A. Beláň, "Global assessment of power system operational state after reconfiguration," Power engineering 2016 - Control of Power Systems, vol. 12, pp. 35-41, May 2016 [12th International scientific conference].

[10]M. Straka, "Rekonfigurácia prenosovej sústavy Slovenskej republiky," Elektroenergetika, vol. 7, pp. 101-104, Sep 2013 [7th International scientific symposium].

[11]M. Jedinák, S. Prieložný, R. Šmidovič, "Topology Changes in the Transmission System of the Slovak Republic," Power engineering 2012 - Control of Power Systems, vol. 10, pp. 1-9, May 2012 [10th International scientific conference]. 